\title{
Implications of Psychosocial Risks Associated with Adolescents' Sports Participation: Need for Sport Counselling
}

\author{
Gloria O. Nwankwo ${ }^{1}$ and Rosemary O. Ekechukwu ${ }^{2}$ \\ ${ }^{1}$ Department of Human Kinetics \& Health Education, University of Port Harcourt, Nigeria \\ ${ }^{2}$ Department of Educational Psychology, Guidance \& Counselling, Faculty of Education, University of Port \\ Harcourt, Nigeria \\ Email: ${ }^{1}$ gloria.nwankwo@uniport.edu.ng, ${ }^{2}$ mamatriplets01@yahoo.com
}

\begin{abstract}
Sports participation is generally appreciated especially when adolescents are involved but the risks associated with this venture are often treated with levity even when it is obvious that they can mar the adolescents' ambition in sports if not well managed. The main thrust of this paper is to identify psychosocial risks associated with adolescents participation in sports and the implications of these risks on sports as a career. In conclusion, it posits that risks associated with sports participation should be identified and analyzed holistically in order to proffer effective management strategies so that the choice of sport as a career would be embraced by adolescents. Its recommendations include: That sports federations should employ safety and counselling personnel to be part of their technical crews who would also be involved in the development of school sports: Adolescent should be sensitized on inherent risks associated with their choice of sport and their role in effective management of the risks. Risk assessment should be conducted for every competition and adequate control measures put in place to minimize risk.
\end{abstract}

Keywords: psychosocial risks, adolescents' sports participation.

\section{Introduction}

Participation in sports has become popular among people of all ages. The rate of adolescents' participant has increased tremendously. Paediator Child Health (2009) noted that there is a high level of adolescence participant in sports. Sports participation although a cherished social activity has risks of diverse nature associated with it especially at the adolescence level.

Risk, according to Wikipedia (2018), is the probability of an unwanted event, intentional interaction with uncertainty, and a consequence of action taken in spite of uncertainty. BBC Bitesize (2009) described risk as the likelihood of something harmful happening .Earlier, International Standards Organization (1S0 3100) (2009) described risk as the effect of uncertainty on goals while Bartesaghi, Grey and Gibson (2012) posited that risk is the interaction between set goals and the likelihood of failure and negative outcomes. Nwankwo (2014) posited that risk is a practice or situation that can increase the chance of undesirable events. Risk in this paper is the probability of occurrence of incidents that can have adverse influence on sports participation.

Hillman (2019) categorized risk in sports participation into biological, physical, psychosocial and socio cultural. This paper is concerned with psychosocial risks of sports participation among adolescents and the need for counselling. Simply put, psychosocial risks are situations and conditions associated with sport participation which may expose the psychological and social well being of participants to danger. In other words, it is the probability of occurrence of events that may negatively affect participants minds set and relationships. The participants in this context are the adolescents.

Adolescents are young people who are at transitional phase of development between late childhood and adulthood usually within the ages of 10-19. Adolescence according to Craskey and Anafara (2014), is a distinct phase of human growth and development when individuals experience rapid and significance developmental characteristics. KKHSOU (2011) described adolescences as the most crucial period of human growth, the period of rapid and revolutionary changes when human personality develops new dimensions. These characteristics require adequate attention so that the adolescents would be fulfilled in 
life. This stage of life manifest a great deal of physical strength and desire for association hence a good number of adolescents find pleasure in sports participation to develop these attributes.

Sports participation which can simply be described as involvement in physical activities is comprehensively conceptualized by the Council of Europe (2001), as casual or organized participation in all forms of physical activities aimed at expressing or improving total well-being, forming social relationships or excelling in competitions at all levels. Langle, Siemssen and Hornberger (2000), observed that sports participation can have effect on several psychosocial domains that are related to participants mental health, self esteem, social interaction among others. In as much as these effects are mostly viewed from the positive angle there is need to consider the psychosocial risks associated with sports participation especially in relation to the adolescents.

\section{Psychosocial Risks Associated with Adolescents Sports Participation}

\subsection{Win at All Costs Mentality}

Adolescents can participate in either casual or organized sports, while casual sports lay little or no emphasis on victory of participants, organized sports place high regard on victory hence participants pay great attention to training before participation. However, the emphasis on winning sometimes goes beyond the adolescents perception and level of understanding hence external pressure from coaches, fans, spectators peer group and sometimes family members expose them to untold humiliation. This situation leaves a negative impression in their young mind which affects the adolescents' feeling and social interaction. Lindholm (2017), posited that a win-at-all cost mentality devastates young athletes while Spongcoach (2017), opined that it teaches the youth that integrity does not mean anything.

\subsection{Outcome of Performance}

Adolescents who participate in organized sports are faced with the option of either victory or defeat. Victory enhances positive emotion while defeat introduces negative emotion which may linger to adulthood if not properly managed. There are situations where an adult would regret involvement in an activity that left him with negative emotions especially these days that technology can aid in watching and recalling past events as if they are current.

Defeat in sports has the potential of not just affecting adolescents confidence negatively but impacting on the adolescents social interaction which may results to withdrawal from relationships as a result of loss of self esteem. Radwan (2017) noted that lack of self confidence introduces doubt in the ability to succeed at anything. In agreement, competitive Advantage (2019) posited that low self esteem can kill an athlete's enjoyment of the sport and facilitate the athletes withdrawal from virtually everything. Most athletes feel great when they win but how they handle loss defines their long-term character (Lindholm, 2017).

\subsection{Dependence on Sports Performance Level}

Many adolescents believe that sports is the only avenue for success especially those with high performance level. They ignore other sources of success including academics, Jayanthi et al (2013), observed that early sports specialization results to increase psychological stress which facilitates drop out at young age. They lose sight of the fact that old age is not friendly with high level of sports performance hence they need other source of livelihood to depend on. Sports performance also declines as a result of injury, ill health, lack of sponsorship among others. Lindholm (2017), commented that there is a likelihood of an athlete facing a sport ending injury or simply burn out. She further noted that putting all eggs in the sports basket is misguided and dangerous to the adolescents emotional well being therefore, adolescents should be guided to other routes to success.

Appreciation of the adolescents should not be tied to high level of sports performance to avoid reactions that may negatively impact on their life. Adolescents actually need encouragement when they fail in any life endeavour, so loss or defeat in sports should attract more love and affection. In other words showing appreciation only when the adolescents excel in sports would have negative influence on 
their decision on sports related issues. Anzilotti (2019), posited that young athletes should be helped to develop healthy attitude towards sports and other skills that enhance their wellbeing.

\subsection{Undue Pressure for Improved Sports Performance}

Basically, the focus of sports participation among adolescents is to provide fun and stay fit although they learn other important virtues that are relevant to their development. Undue pressure and much emphasis on high level performance have drained these values and negatively showcase sports emphasizing the stress associated with the achievement of high level of sports performance. In as much as the human body needs stress to face changes of life, Anzilotti (2019), stated that too much stress can take the fun out of sports and make it hard to perform. The pressure for enhanced performance come mostly from coaches, family members peers and others who really impact negatively on the psychosocial well-being of the adolescents. There is an inordinate amount of pressure to successful performance for not just the adolescents but the coaches and school officials (Chachkes (2010). Sports has become too serious, competitive and adult driven (New York Times, 2010) with little or no consideration for the adolescents benefits with the presence of undue pressure from relevant others, adolescents may resort to negative means to succeed.

\subsection{High Sense of Superiority Complex}

Some adolescents feel they are superior to their contemporaries who cannot perform at their level in sports. Some of these athletes extend this attitude to people who would have helped them later in life. They consciously or unconsciously allow their performance level to becloud their reasoning which they may regret in adulthood and remain in self-pity when they realize that their success in life was hampered by their attitudes. Adolescents stand the risk of mismanaging their success in sports if not well guided. Their developmental characteristics deny them the ability for logical reasoning hence high sports performance can be disadvantageous to them. Some successful adolescent athletes project themselves as outlaws and they exhibit this attitude without remorse. The society, to an extent over emphasize the appreciation of their success by giving them certain preileges which seem to justify their negative attitude. Commenting on this, Lindholm (2017), said that sports should not bring out the worst in the adolescents.

\subsection{Sports Environment}

Participation in sports exposes adolescent to conditions, situations and circumstances which make them prone to social vices of diverse nature. In most cases, they are meant to take vital decisions on issues they do not really understand their implications. For instance, many adolescents are into substance abuse and addiction just because the coach or team mates introduced them to it for improved performance. Some of these adolescents become violent as a result of the effect of the substance. Others are susceptible to sexual abuse and harassment by the officials of their teams who actually suppose to take care of them. According to fasting (2005), the young athletes are trapped by using threats or given special privileges.

Participation in sports competitions held in volatile environments can make adolescents vulnerable to kidnapping and terrorists' attacks. Volatile environments precipitates violence which can be in different forms and proportions. Adolescents can become enraged when they lack the impulse control to deal constructively with perceived threat (Heinzmann, 2019). Even the friends they meet and the places they visit in course of sports competitions have the potential of negatively impacting on their psychosocial well being and their every need for counsellors to assist them to be security conscious.

\subsection{Influence of the Media}

The media reports in some cases contradict the actual facts of incidents they report in sports. The adolescents who may never have access to the real facts would be at risk of mutilated information which eventually impacts on their disposition. On the other hand, adolescent athletes who watch or read media reports that contradict facts they have first hand information on, would have their interest in sports 
being at risk. Also, adolescents who watch their sports models engaging in violence of any kind during sports participation would believe that violence is part of sports. Famous athletes have become role models for many individuals especially children and adolescents (Paynee et al 2003). Even violence in elite sports that are reported in the media negatively influence the psychosocial well being of the adolescent athlete.

Over publicity of successful adolescent athletes has its own negatibvely on the psychosocial well being of the adolescents. High publicity of adolescents in sports has resulted to some of them dropping out of school and other trades through which they would have been successful in life. The media has largely contributed to misinterpretation of adolescents' success in sports. Affolter (2017), noted that of all sports media's spectators, the young are the most easily influenced while earlier, Nicely (2007), stated that the media frames can damage young people's athletic promise by giving falsehope.

\section{$3 \quad$ Implications of Psychosocial Risks}

Based on the concept of psychosocial risks in this paper, it is imperative to state that the implications of the psychosocial risks refer to impending effects of adolescents' participation in sports.

Adolescents have been conceptualized as young people who are at transitional phase of human development. Psychosocial development is a major characteristic of this stage of human life. The adolescents are the future generation on whom both the continuity of human race and activity rely on. Sports is a celebrated human activity which adolescents can optimally utilize if the opportunities are properly and effectively harnessed. Participation in sports which obviously helps adolescents in their psychosocial development can also expose them to risks that can devastate their interest and shatter their ambition towards the choice of sports as a laudable career.

The psychosocial risk identified in this paper have the potential of constituting serious cog on the wheel of choice of sports as a career among adolescents who are not generally used to verbalize or intellectualize their experiences (Moreau et al, 2017).

Psychosocial risks associated with adolescent sports participation can facilitate premature retirement of adolescents in sports. When a young athlete who devotes time, energy and resources on developing necessary skills and techniques of a chosen sport suddenly ends participation due to exposure to any of these risks, the athlete becomes devastated because of the deep sense of loss. The situation introduces which affects the athletes' relationship and people's perception of him. Excel At Life (2002) stated that when sports career suddenly ends, it leaves a major hole in the athletes' life. The athlete experiences a significant loss like that of a loved one. Any athlete who experiences such may not only abandon sports but could vehemently discourage those around him who would want to choose sports as a career.

On the other hand, adolescents who eventually accepts sports as a career inspite of their exposure would likely increase the level of these risks. The young usually either by accident or design try to explore whatever knowledge they acquire and this affects them negatively or positively. An adolescent athlete whose coach introduced to performance enhancing substance would likely seek and probably discover a higher version of such which might not be properly dispensed, the outcome is obvious. Consequently, sports as a career for such a victim would be an illusion. Gruber and Grube (2000) noted that adolescents are at risk because their cognitive skills that would enable them to take decisions based on possible future outcomes are not fully developed

\section{Conclusion}

Sports participation is highly appreciated by virtually everyone and it is mostly applauded when young people are involved. Therefore, the young should be encouraged to participate in sports in order to create excitement for all and nurture the future of sports as a laudable career.

Psychosocial dimension is strategic in the development of values and appreciation among the adolescents hence concerted efforts should be made to effectively manage the risks associated with it in all spheres of the adolescents' life. Adolescents attitudes and behaviour towards sports especially in adulthood would be greatly determined by its worthwhile in active participation. US National Library of Medicine (2018) posited that adolescents participation in sports is a predictor of active lifestyle in 
adulthood which help to prevent many health problems. This implies that adolescents participation in sports has the potential to reduce health risks at adulthood.

Adolescent period as a formative stage of life play a vital role in life decisions therefore negative impressions of sports at this stage would definitely impact on the adolescents ambition in sports as a career. Every human endeavour need the young to blossom, sport as laudable human endeavour should be saved from impending danger of psychosocial risks associated with it especially at the adolescent extrication by effective management of psychosocial risks associated with it, especially at the adolescents participation level.

Risks can be managed if properly classified and appropriate measures taken. Risks associated with adolescents sports participation should be classified as high risks since they are capable of destroying the future of sports. Therefore, urgent attention is eminent in this regard in order to save sports globally.

\section{$5 \quad$ Recommendations}

This paper recommends as follows:

1) Adolescent sports teams should have sports counsellors and safety professionals as part of their team officials.

2) Adolescent sport competitions should incorporate safety talks and counselling as part of their programme.

3) Safety professionals in collaboration with professionals in sports and counselling should mount school and public awareness on sports safety.

4) Safety professionals and sports counsellors should organize sports based training for school authorities and sports officers to enhance sports safety in schools.

5) Organizers of adolescent sports should ensure that risks associated with sports competition are classified and appropriate measures are taken to reduce the risk as low as reasonably practicable.

6) Stakeholders in sports and safety should not treat risks associated with sport with levity.

\section{References}

1. Affolter, F. (2017). The effects of sports media on children's sports participation. The influence of gender and social background. www.researchgate.net.

2. Anzilotti, A. W. (2019). Competitive sports: Helping kids play it cool. https://kidshealth.org $>$ sports competition.

3. Bartesaghi, M. Grey, S. H. \& Gibson, S. (2012). Define (the concept of) risk. An Inter Journal of Rehetoricals Analysis and Invention. 8(1). https://doi,org/10,1308/2151-295-7.1112.

4. BBC Bite (2019). GCSE Physical Education-Prevention of injury https://www.bbc.com>guides $>$ revision.

5. Caskey, M. M. \& Anfara, V. A. (2014). Developmental characteristics AMLE of young adolescents. www.amle.org.

6. Chachkes, B. (2010). Violence in youth sports: A growing trend? A downward spiral and a young man's brutalization. www.mysports.day.com.

7. Competitive Advantage (2019). Self confidence, peak performance and mental tonghness www.competitive.com.

8. Council of Europe (2001). Concept of sports participation. The Europe Sport Character Council of Europe. www.coe.int.

9. Excel Alife (2002). Issues when ending a sports career. https://www.excelalife.com.article...

10. Fasting, K. (2005). Sexual harassment and abuse in sports.www.idrottsforum.org.

11. Gruber, E. \& Grube, J. W. (2000). Adolescent sexuality and the media. A review of current knowledge and implications. West J. Med. 172(3), 201-214 https://www.ncbi.nim.nih.gov>article.

12. Heinzmann, G. S. (2019). Parental violence in sports: Facts, myth and video tape. Youth Sports Rutgers rutgers.edu.

13. Hillman, S. K. (2019). Reorganizing the factors that contribute to sports injury risk. Human kinetics. www.humankinetics.com exposure $>$ rec...

14. Janyanthi, N. Pinkham, C., Dugas, L. Patrick, B. \& Labella, C. (2013). Sports specialization in young athletes evidence-based recommendations. Sports Health (PMC freearticles) (PubMed) (cross Ref). 
15. Krisha Kanta Kandiou State Ofile University (KKHSOU) (2011). Introduction to adolescence stage. www.kkhsou.edu>intro..

16. Langle, G, Siemsen, G., Hornbergers, S. (2000). The role of sports in the treatment and rehabilitation of schizophrenic patients. Rehabilitation. 39(5)276-282.

17. Lindholm, M. (2017). The pros and cons of youth sports aren't only physical. Today psychology. www.psychology.

18. New York (2013). Can playing ball be bad for children? http://www.nytimes.com/room fordebate/childrenssports life.

19. Nicely, S. (2007). Media framing of female athletes and women's sports in selected sports magazines. www.researchgate.net

20. Paediator Child Health (2009). Sport participation, sport injury, risk factors and sport safety practices in calgang and area junior high schools. www.ncbinlm.nih gov.

21. Payne, W, Reynolds, M, Brown, S. \& Fleming, A. (2003). Sports role models and their impact on participation in physical activities: A literature review. Victoria: VicHealth, 74.

22. Radwan, M. F. (2017). Lack of self confidence and sports 2 know my self. www.2know myself.com

23. Spong Coach (2017). The "winning at all cost" virus continues to grow in youth sports and its up coaches that can check their egos to eradicate it. www. Sponcoach.com.

24. US National Library of Medicine (2018). Temporal trends in sports participation among adolescents. Int. J. Environ. Res-public Health. 15(7) www.ncbi.nlm.nihgov.

25. Wikipedia (2018). Risk. https://en.org $>$ wiki $>$ Risk. 